\title{
Effects of different manufacturing methods on pharmaceutical properties and release kinetic models of ketoprofen sustained-release microparticles
}

\author{
Thau-Ming Cham ${ }^{1}$, Shiao-Feng Huang ${ }^{2}$, Tong-Rong Tsai ${ }^{1}$, Yuh-Tyng Huang ${ }^{3}$, \\ and Wen-Ho Chuo ${ }^{4}$
}

\footnotetext{
${ }^{1}$ School of Pharmacy, Kaohsiung Medical University, No.100 Shih-Cheun 1st Road, Kaohsiung, Taiwan, R.O.C. ${ }^{2}$ Department of Pharmacy, Chi-Mei Medical Center, No.901 Zhonghua Road, Yongkang District, Tainan, Taiwan, R.O.C.

${ }^{3}$ Departmane of Pharmaceutical Science and Technology, Chung Hwa University of Medical Technology, No.89 Wenhwa 1st Street, Rende Shiang, Tainan County, Taiwan, R.O.C.

${ }^{4}$ Department of Pharmacy, Tajen University, No.20, Weixin Road, Yanpu Township, Pingtung County, Taiwan, R.O.C.
}

Accepted 14 September, 2012

\begin{abstract}
Extrusion-spheronization and the fluid bed method are valuable commonly applied methods in microparticle production. However, the characteristics of resultants prepared by these two methods have seldom been compared. The aim of this study was to investigate differences in pharmaceutical properties and release kinetics of sustained-release ketoprofen microparticles prepared by different manufacturing processes. Microparticles prepared by extrusion-spheronization displayed slower release rate resulting in increased diffusion path of the drug, a behavior distinct for microparticles with less Surelease ${ }^{\circledR}$. The effects of manufacturing method on release rate was also significant for microparticles with less Surelease ${ }^{\circledR}$ compared to microparticles with more Surelease ${ }^{\circledR}$. The release profiles of coated microparticles fitted well to the Higuchi's release model, but in cases of microparticles with larger Surelease ${ }^{\circledR}$ coating, the trend was towards a zero-order release model. These findings are valuable for comprehending the differences among different preparation processes and for choosing the optimal manufacturing method of sustained-release microparticles.
\end{abstract}

Key words: Ketoprofen, microparticles, sustained drug delivery, extrusion-spheronization, fluid-bed, dissolution release kinetics.

\section{INTRODUCTION}

To improve efficiency and patient compliance, numerous oral sustained-release dosage forms are used in many therapeutic applications. Multiple-unit sustained-release dosage forms like microparticles are receiving greater attention due to advantages, such as flexibility during formulation development, that reduce batch-to-batch variability (Bodea and Leucuta, 1998; Ansel et al., 1999;

${ }^{*}$ Corresponding author: E-mail: cwh@mail.tajen.edu.tw. Tel: +886-8-762-4002. Fax: +886-7-558-5515.
Bodea and Leucuta, 1997; Hamdani et al.,1996).Drug absorption is also enhanced via increased surface area than single-unit dosage forms, reduced risk of side effects by decreased possibility of dose-dumping associated with single-unit sustained release tablets, and reduced peak plasma fluctuations resulting in more stable drug absorption (Follonier and Doelker, 1992). Extrusionspheronization and fluid bed method are the most commonly used techniques in micro-particulate drug delivery systems in the pharmaceutical industry because of advantages, which include convenience, reproducibility, and good control of process parameters (Esposito 
et al., 2000; Blanque et al., 1995; Gandhi et al., 1999; Tapia et al., 1993). Moreover, extrusion-spheronization and fluid bed technology are practical for high drug-load pellets and thus, are suitable for sustained-release dosage forms in which drug content is higher than conventional short-acting dosage forms (Hileman et al., 1993). Currently, their applications are not only in the pharmaceutical industry but in food and agriculture (Marmo, 2007; Jiménez-Aguilar et al., 2011).

Although different papers report on different preparation methods of sustained-released dosage forms, there has been no comparison of release-controlling characteristics of extrusion-spheronization and fluid bed method to date. The aim of this study was to compare the pharmaceutical properties and release kinetic models of different types of ketoprofen sustained-release formulations prepared by the two different methods. Ketoprofen, an effective nonsteroidal anti-inflammatory and analgesic agent used to treat acute and chronic rheumatoid arthritis and osteoarthritis, was chosen as a suitable drug for investigation because of its short half-life $(1 \mathrm{~h})$ and irritating effects on gastric mucosa (Vergote et al., 2001; Hassan et al., 1995). Since pharmaceutical properties like elongation, particle size, and yield percentage of pellets prepared by extrusion-spheronization are influenced by complex process conditions, an L16 $\left(2^{15}\right)$ orthogonal array design was employed to investigate production and processing parameters affecting resultant microparticles and to determine the optimal formulation.

\section{MATERIALS AND METHODS}

Ketoprofen powders were purchased from Wuxue Xunda Pharmaceutical Co. (China), while ketoprofen and fenoprofen were purchased from Sigma Chemical Co. (U.S.A.) and used as standard and internal standard for high performance liquid chromatography (HPLC) analyses, respectively. Comprecel ${ }^{\circledR}$ M102 (MCC) was purchased from Mingtai Chemical Co.(Taiwan) and Oruvail $200^{\circledR}$ from Brenntag Chemicals Co. (Taiwan). Non-pareil seeds (25-30\#) (IPS. (srl.), Milano, Italy) and Surelease ${ }^{\circledR}$ (Colorcon, Japan) were used as supplied, while PVP K30 (Kollidon 30) were purchased from BASF Chemical Co. (Germany). All other chemicals were of analytic grade.

\section{Differential scanning calorimetry}

Interactions between active ingredients and excipients were measured by differential scanning calorimetry (model DSC 7 Perkin-Elmer, U.S.A.). The physical mixtures of ketoprofen and excipients (MCC, PVP K30, Surelease ${ }^{\circledR}$, starch, and talc) were dried in a vacuum oven at $40^{\circ} \mathrm{C}$ for $24 \mathrm{~h}$ to remove water from the samples. Each sample $(6 \mathrm{mg})$ was placed in sealed flat-bottom aluminum sample pans and scanned from 50 to $300^{\circ} \mathrm{C}$ at a heating rate of $10^{\circ} \mathrm{C} / \mathrm{min}$. The microparticles prepared by different methods (F-S 50 and E-S 50) were grounded to powder form for DSC examination and the results were compared with individual DSC thermograms.

\section{Solubility test}

Since ketoprofen is poorly soluble in acidic conditions, the addition of surfactant may increase solubility and release rate for optimal bioavailability (Jinno et al., 2000; Vergote et al., 2002). In this study, a pre-formulatory study of different concentrations of surfactants on the equilibrium solubility of ketoprofen in different $\mathrm{pH}$ medium was conducted. For this, $0.1 \mathrm{~g}$ ketoprofen was added to $15 \mathrm{ml}$ varying media $(\mathrm{pH} 1.2,4.6,6.8$, and 7.4$)$ of different surfactants (1\% sodium lauryl sulfate or $5 \%$ PVP K30). The samples were placed on a shaker and agitated at $37^{\circ} \mathrm{C}$, withdrawn at $6,8,10,12,24,36,48$, and $72 \mathrm{~h}$, and centrifuged at $10000 \mathrm{rpm}$. The supernatants were then analyzed by HPLC.

\section{Preparation of ketoprofen-loaded microparticles by extrusion- spheronization}

The four main processing steps of extrusion-spheronization (E-N) method are blending, wet mixing, extrusion of wet mass into short cylinders, and spheronization of the extrudate using a spinning friction plate. Ketoprofen powder $(40 \%)$ was previously mixed with PVP K30 (2\%) and sodium lauryl sulfate $(0.5 \%)$, which were added in the manufacturing process to improve the dissolution behavior, and excipients (MCC $50.5 \%$, starch $5 \%$, and talc $2 \%$ ) for $5 \mathrm{~min}$ in a mixer (model KSMC50, Taiwan). The required amounts of water were then added to the dry blends and mixed for an additional 10 min to produce a wet mass, which was passed through an screw extruder (model SY-86070-4, Taiwan), the length of screen bores were 1.0 and $1.5 \mathrm{~mm}$. The extrudate was processed in a spheronizer (model SY-86070-3, Taiwan), which consists of a rotating friction plate and spins at high speed at the bottom of cylindrical bowl, using different speeds for different spheronization times.

During the course of extrusion and spheronization, the microparticles properties were affected by different preparation situations. The characteristics of coated resultants were affected by pharmaceutical properties (e.g. elongation and particle size) of uncoated microparticles. To determine the effects of manufacturing processes and conditions on pharmaceutical properties of products and to obtain optimal manufacturing conditions, an L16 $\left(2^{15}\right)$ orthogonal array experimental design method was applied for an overall investigation. The experimental variables and design matrix were given in Tables 1 and 2 . Six important variables in the manufacturing process - amount of water content (variable A), amount of binder (variable B), extrude speed (variable C), extrude screen size (variable D), spheronization speed (variable E), and spheronization time (variable $F$ ) - and three interactions (variable $A \times B$, variable $\mathrm{C} \times \mathrm{D}$, and variable $\mathrm{E} \times \mathrm{F}$ ) were chosen to investigate the effect on elongation and yields of microparticles. Each variable occurred at two suitable levels (low level [1], high level [2]). For example, variable A represents amount of water content, low level and high level express 120 and $135 \mathrm{ml}$ respectively (Table 1). In the first experiment (Run 1) as shown in Table 2, variables A, B, C and D are all low level, that is to say, $120 \mathrm{ml}$ water and $1 \mathrm{~g}$ binder were used to make wet mass, then the wet mass was passed through an extruder of $1.0 \mathrm{~mm}$ screen size and the extrude speed was $30 \mathrm{rpm}$. The extrudate was processed in a spheronizer under $600 \mathrm{rpm}$ for 5 min, and the resultant pellets were dried in a hot air oven and collected. In total, 16 experiments were performed in random order. The experimental results were analyzed with the design-expert ${ }^{\circledR}$ software (version 6) and data were compared statistically using analysis of variance (ANOVA) (Abdullah and Al-Khamis, 1993). According to the analyses earlier described, ketoprofen-loaded core microparticles (E-N) were prepared under optimal conditions and dried in a hot air oven at $40^{\circ} \mathrm{C}$ for further coating process.

Preparation of ketoprofen-loaded microparticles by fluid bed method

Ketoprofen-loaded microparticles were prepared by coating 
Table 1. Two levels of six variables in the experimental design.

\begin{tabular}{lcc}
\hline Variables & Low level (1) & High level (2) \\
\hline A: Amount of water content $(\mathrm{ml})$ & 120 & 135 \\
B: Amount of binder $(\mathrm{g})$ & 1 & 4 \\
C: Extrude speed $(\mathrm{rpm})$ & 30 & 60 \\
D: Extrude screen $(\mathrm{mm})$ & 1 & 1.5 \\
E: Spheronization speed $(\mathrm{rpm})$ & 600 & 1100 \\
F: Spheronization time $(\mathrm{min})$ & 5 & 10 \\
\hline
\end{tabular}

Table 2. Experimental design matrix of the $L_{16}\left(2^{15}\right)$ orthogonal table.

\begin{tabular}{|c|c|c|c|c|c|c|c|c|c|c|c|c|c|c|c|}
\hline Run & $\begin{array}{l}A \\
1\end{array}$ & $\begin{array}{l}\text { B } \\
2\end{array}$ & $\begin{array}{l}A \times B \\
3\end{array}$ & $\begin{array}{l}\text { C } \\
4\end{array}$ & $\begin{array}{l}\text { error } \\
5\end{array}$ & $\begin{array}{l}E \times F \\
6\end{array}$ & $\begin{array}{l}\text { error } \\
7\end{array}$ & $\begin{array}{l}D \\
8\end{array}$ & $\begin{array}{l}\text { error } \\
9\end{array}$ & $\begin{array}{l}\text { error } \\
10\end{array}$ & $\begin{array}{l}F \\
11\end{array}$ & $\begin{array}{l}C \times D \\
12\end{array}$ & $\begin{array}{l}E \\
13\end{array}$ & $\begin{array}{l}\text { error } \\
14\end{array}$ & $\begin{array}{l}\text { error } \\
15\end{array}$ \\
\hline 1 & 1 & 1 & 1 & 1 & 1 & 1 & 1 & 1 & 1 & 1 & 1 & 1 & 1 & 1 & 1 \\
\hline 2 & 1 & 1 & 1 & 1 & 1 & 1 & 1 & 2 & 2 & 2 & 2 & 2 & 2 & 2 & 2 \\
\hline 3 & 1 & 1 & 1 & 2 & 2 & 2 & 2 & 1 & 1 & 1 & 1 & 2 & 2 & 2 & 2 \\
\hline 4 & 1 & 1 & 1 & 2 & 2 & 2 & 2 & 2 & 2 & 2 & 2 & 1 & 1 & 1 & 1 \\
\hline 5 & 1 & 2 & 2 & 1 & 1 & 2 & 2 & 1 & 1 & 2 & 2 & 1 & 1 & 2 & 2 \\
\hline 6 & 1 & 2 & 2 & 1 & 1 & 2 & 2 & 2 & 2 & 1 & 1 & 2 & 2 & 1 & 1 \\
\hline 7 & 1 & 2 & 2 & 2 & 2 & 1 & 1 & 1 & 1 & 2 & 2 & 2 & 2 & 1 & 1 \\
\hline 8 & 1 & 2 & 2 & 2 & 2 & 1 & 1 & 2 & 2 & 1 & 1 & 1 & 1 & 2 & 2 \\
\hline 9 & 2 & 1 & 2 & 1 & 2 & 1 & 2 & 1 & 2 & 1 & 2 & 1 & 2 & 1 & 2 \\
\hline 10 & 2 & 1 & 2 & 1 & 2 & 1 & 2 & 2 & 1 & 2 & 1 & 2 & 1 & 2 & 1 \\
\hline 11 & 2 & 1 & 2 & 2 & 1 & 2 & 1 & 1 & 2 & 1 & 2 & 2 & 1 & 2 & 1 \\
\hline 12 & 2 & 1 & 2 & 2 & 1 & 2 & 1 & 2 & 1 & 2 & 1 & 1 & 2 & 1 & 2 \\
\hline 13 & 2 & 2 & 1 & 1 & 2 & 2 & 1 & 1 & 2 & 2 & 1 & 1 & 2 & 2 & 1 \\
\hline 14 & 2 & 2 & 1 & 1 & 2 & 2 & 1 & 2 & 1 & 1 & 2 & 2 & 1 & 1 & 2 \\
\hline 15 & 2 & 2 & 1 & 2 & 1 & 1 & 2 & 1 & 2 & 2 & 1 & 2 & 1 & 1 & 2 \\
\hline 16 & 2 & 2 & 1 & 2 & 1 & 1 & 2 & 2 & 1 & 1 & 2 & 1 & 2 & 2 & 1 \\
\hline
\end{tabular}

ketoprofen solution onto non-pareil beads (25-30\#) using a fluid-bed apparatus (model YC-FBDG-2, Taiwan). After PVP K30 (38 g) was dissolved in $1200 \mathrm{ml}$ water, ketoprofen $(200 \mathrm{~g})$, talc $(2 \mathrm{~g})$, starch (5 g) and sodium lauryl sulfate $(5 \mathrm{~g})$ were added and the resultant dispersion was stirred completely and passed through a 200-mesh sieve. Subsequently, a pre-formulatory study was undertaken to obtain optimal processing conditions. The ketoprofen-loaded core microparticles were produced by spraying the dispersion on nonpareil seeds (25-30 \#) using the following instrumental settings: feeding rate of the dispersion $10 \mathrm{rpm}$, inlet temperature of the drying air $30^{\circ} \mathrm{C}$, and outlet temperature $45^{\circ} \mathrm{C}$. The microparticles were collected and dried in a hot air oven at $40^{\circ} \mathrm{C}$ for further coating process.

\section{Preparation of sustained-release ketoprofen microparticles}

Surelease ${ }^{\circledR}$, an aqueous dispersion of ethylcellulose and one of the most widely used water-insoluble coating polymers in sustainedrelease dosage forms, was chosen for its excellent physic-chemical stability, good flexibility, and minimum toxicity (Shailesh et al., 2010). To explore its influence on dissolution characteristics, different amounts of Surelease ${ }^{\circledR}(20$ and $50 \mathrm{~g})$ were diluted with water to make $60 \% \mathrm{w} / \mathrm{w}$ coating solution, which was sprayed on previously prepared microparticles (E-N and $\mathrm{F}-\mathrm{N}$ ) to obtained different sustained-release microparticles. Known weights of ketoprofen pellets $(200 \mathrm{~g})$ were transferred into a fluid bed apparatus with the following instrumental settings: feeding rate of the dispersion $10 \mathrm{rpm}$, inlet temperature of the drying air $40^{\circ} \mathrm{C}$, while the outlet temperature was $50^{\circ} \mathrm{C}$. The uncoated $(\mathrm{E}-\mathrm{N}$ and $\mathrm{F}$ $\mathrm{N}$ ) and coated (E-S 20, E-S 50, F-S 20, F-S 50) microparticles were collected and filled into $0 \#$ capsules for dissolutions studies. The amount of ketoprofen in the capsules was held constant at $200 \mathrm{mg}$, while the total weight varied (E-N, $500 \mathrm{mg}$; E-S 20, $520 \mathrm{mg}$; E-S 50, $550 \mathrm{mg}$; F-N, $450 \mathrm{mg}$; F-S 20, $470 \mathrm{mg}$; and F-S 50, $500 \mathrm{mg}$ ). The compositions of the different formulations were listed in Table 3.

\section{Properties of ketoprofen sustained-release microparticles}

\section{Morphologic characterization of microparticles}

The morphology of intact microparticles was investigated using both optical microscopy and scanning electron microscopy (model JSM 5300, Japan). An elongated character was selected to determine the shape of microparticles.

\section{Elongation analysis}

Pellet elongation was evaluated by optical microscopic imaging. The image analyzer is equipped with a computer system linked to a video camera and a microscope (magnification $\times 40$ ). The elongation character was calculated as the max diameter $\left(R_{1}\right)$ divided by the min diameter $\left(R_{2}\right)$ of microparticles (Hellén and Yliruusi, 1993; Koo and Heng, 2001; Baert et al., 1993; Otsuka et 
Table 3. The compositions of different formulations prepared by extrusion-spheronization and fluid-bed methods.

\begin{tabular}{lcccccc}
\hline Formulations & E-N & E-S 20 & E-S 50 & F-N & F-S 20 & F-S 50 \\
\hline Ketoprofen $(\mathrm{g})$ & 200 & 200 & 200 & 200 & 200 & 200 \\
non-pareil beads $(\mathrm{g})$ & - & - & - & 200 & 200 & 200 \\
MCC $(\mathrm{g})$ & 252.5 & 252.5 & 252.5 & - & - & - \\
PVP K 30 $(\mathrm{g})$ & 10 & 10 & 10 & 38 & 38 & 38 \\
Talc $(\mathrm{g})$ & 10 & 10 & 10 & 2 & 2 & 2 \\
Starch $(\mathrm{g})$ & 25 & 25 & 25 & 5 & 5 & 5 \\
Sodium lauryl sulfate $(\mathrm{g})$ & 2.5 & 2.5 & 2.5 & 5 & 5 & 5 \\
Water (ml) & 337.5 & 337.5 & 337.5 & 1200 & 1200 & 1200 \\
Surelease $^{\circledR}$ (g) & 0 & 20 & 50 & 0 & 20 & 50 \\
\hline
\end{tabular}

al., 1994) as shown in Equation 1. At least 70 microparticles for each sample were determined.

$E=R 1 / R 2$

\section{Size distribution of microparticles and yields analysis}

The various batches were fractioned into eight particle size ranges using 1400, 1180, 1000, 850, 710, 600, and $425 \mu \mathrm{M}$ sieves on a moving sieve shaker (Retch Co., Ltd., Germany) for 15 min. The microparticles obtained from these various sieves were weighed and the yield $(\% \mathrm{w} / \mathrm{w})$ was calculated as the weight of the most fraction microparticles obtained from size analysis distribution divided by the sum of the total weight of the microparticles.

\section{Content uniformity of microparticles}

To determine the amount of ketoprofen in the microparticles, the contents of different capsules were put in a flask and $100 \mathrm{ml}$ methanol was added. The mixture was then sonicated. After centrifugation, the whole supernatant was collected and examined by photo-spectrometry at $254 \mathrm{~nm}$.

\section{Drug release studies}

In vitro release profiles of microparticles prepared by different methods were compared with a commercially available formulation (Oruvial $200^{\circledR}$ ). Dissolution studies were conducted using a standard USP XXIV dissolution apparatus with paddle method for different capsules. The temperature of the dissolution medium was maintained at $37 \pm 0.5^{\circ} \mathrm{C}$ and the rotation speed of the paddle was adjusted to $100 \mathrm{rpm}$. Capsules were introduced in $900 \mathrm{ml}$ of $\mathrm{pH} 1.2$ hydrochloride solution or $\mathrm{pH} 6.8$ phosphate buffer medium. Subsequently, the samples $(5 \mathrm{ml})$ were withdrawn at specific time intervals $(10,20,30 \mathrm{~min}$ and 1, 2, 4, 6, 8, 10, 12, 14, 16, 18, 20, and $24 \mathrm{~h}$ ) and analyzed by HPLC at $254 \mathrm{~nm}$. The withdrawn samples were immediately replaced with fresh dissolution medium. All experiments were performed in triplicate. The dissolution characteristics were compared by using difference factors $\left(f_{1}\right)$ and similarity factor $\left(\mathrm{f}_{2}\right)$, the two fit factors are defined by the equations (Polli et al., 1997; Goskonda et al., 1998):

$$
f_{1}=\frac{\sum_{t=1}^{n}\left|R_{t}-T_{t}\right|}{\sum R_{t}} \times 100 \%
$$

$$
f_{2}=50 \log \left\{\left[1+\frac{1}{n} \sum_{t=1}^{n}\left(R_{t}-T_{t}\right)^{2}\right]^{-0.5} \times 100\right\}
$$

Where $n$ is the number of dissolution sample times, $R_{t}$ and $T_{t}$ are the cumulative percent released at each time point for the reference and test products, respectively. The $f_{1}$ value was zero when the test and reference profiles were identical and increased proportionally with dissimilarity between the two profiles. On the other hand, the $f_{2}$ value was 100 when the profiles were identical. An $f_{2}$ value between 50 and 100 suggested that the two dissolution profiles were similar.

\section{Dissolution release kinetics}

To study the mechanism of drug release from different microparticles, drug release data were analyzed according to zeroorder, first-order, Higuchi and Korsmeyer-Peppas model. The equations were described as follows (Higuchi, 1963; Korsmeyer et al., 1983; Costa and Sousa, 2001):

Zero-order model: $\mathrm{Q}_{\mathrm{t}}=\mathrm{k}_{0} \mathrm{t}$

First-order model: $\ln Q_{t}-\ln Q_{0}=k_{1} t$

Higuchi model: $Q_{t}=k_{H} t^{1 / 2}$

Where $Q_{t}$ is the amount of drug released at time $t, Q_{0}$ is the amount of drug released at time $t=0, k_{0}$ is the zero order release constant, $k_{1}$ is the first order release constant, $k_{H}$ is the Higuchi release constant. Furthermore, to confirm the mechanism of drug release, the first $60 \%$ of drug release was fitted in Korsmeyer-Peppas model (Korsmeyer et al., 1983):

Korsmeyer-Peppas model: $M_{t} / M_{\infty}=k t^{n}$

Where $M_{t}$ is the amount of drug released at time $t, M_{\infty}$ is the amount of drug release after infinite time, $k$ is the rate constant and $n$ is used to characterize different release mechanisms. In the case of a thin film, the $\mathrm{n}$ value for delivery systems in which drug release is primarily controlled by Fickian diffusion is 0.5 and for systems in which non-Fickian transport occurs, $n$ will lie between 0.5 and 1.0, whereas $n=1$ to case-II transport (zero order release) (Lee, 1985). In the case of a cylinder and a spherical matrix, Fickian diffusion is predominant when $n=0.45$ and 0.43 instead of 0.5 , and for Case II transport when $n=0.89$ and 0.85 , instead of 1.0 (Ritger and Peppas, 1987a, 1987b). 
(a)

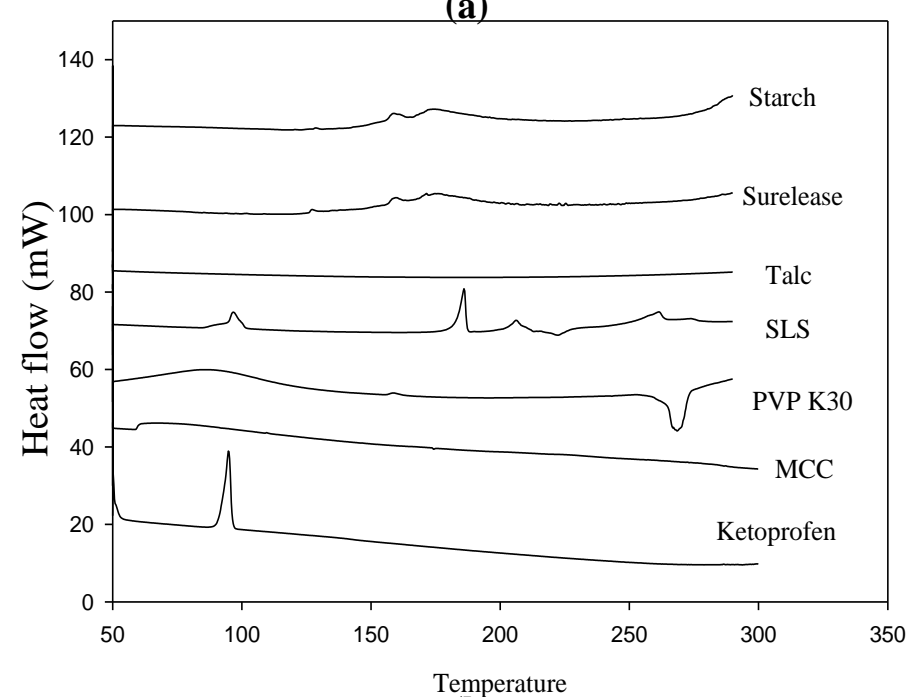

(b)

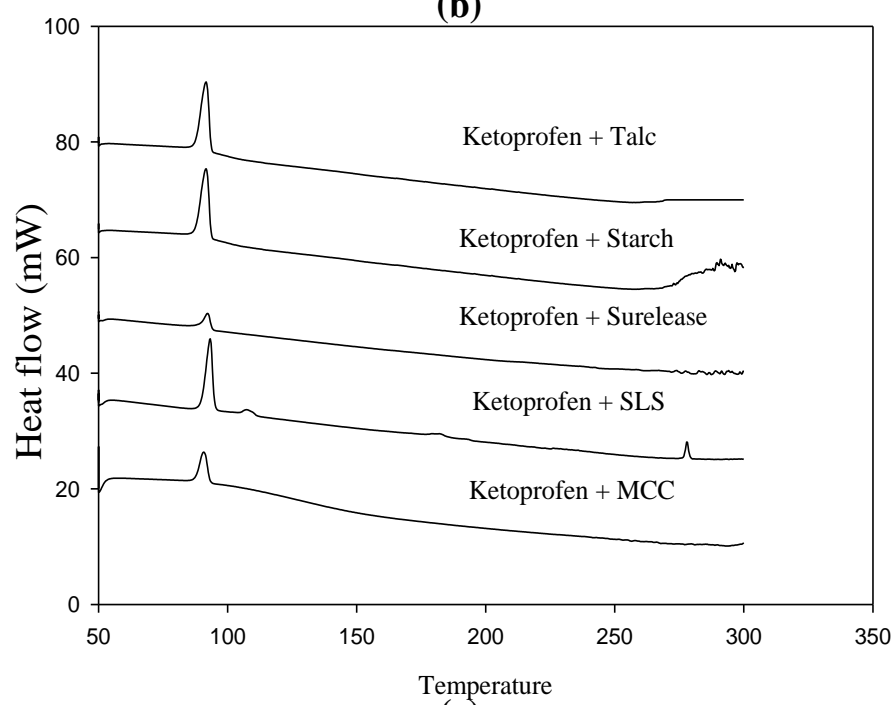

(c)

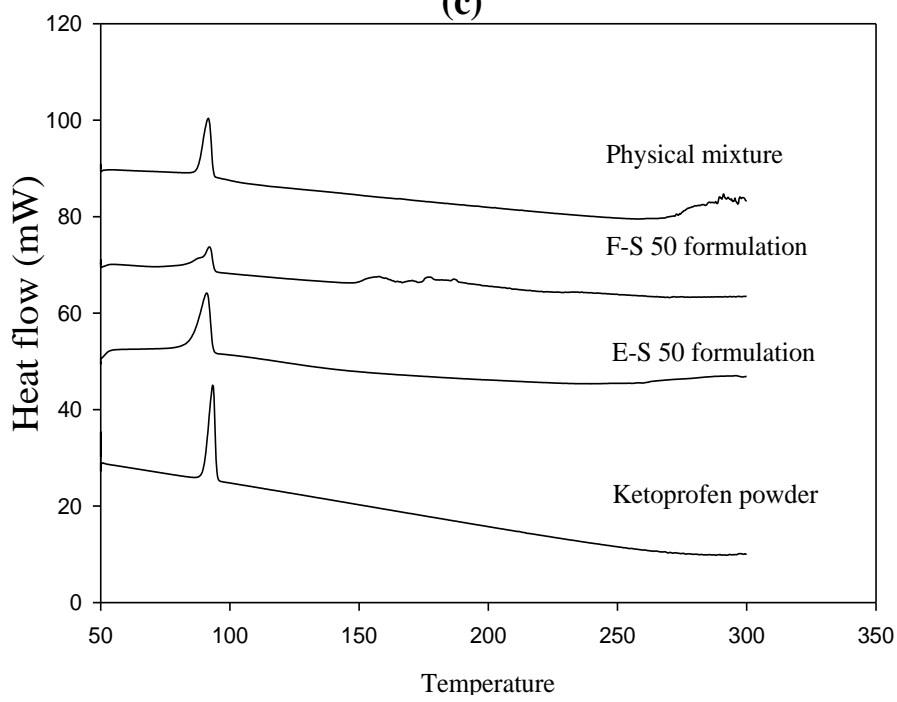

Figure 1. (a) DSC thermogram of ketoprofen and different excipients. (b) DSC thermogram of mixtures of ketoprofen and different excipients. (c) DSC thermogram of sustained release microparticles prepared by different methods (E-S 50 and F-S 50).

\section{RESULTS}

\section{Differential scanning calorimetry (DSC)}

Differential scanning calorimetry (DSC) was employed to explore the possible interaction between active ingredient (ketoprofen) and different excipients. The thermal curve of ketoprofen showed a sharp endothermic peak at $94^{\circ} \mathrm{C}$ (Figure 1a), which persisted at the thermogram of the mixture of ketoprofen and all excipients (MCC, PVP K30, Surelease ${ }^{\circledR}$, starch, and talc) used in this study (Figure 1b). Moreover, the DSC thermogram of two microparticles prepared by different methods (F-S 50 and E-S 50) showed no appearance, shift, or disappearance of peak at $94^{\circ} \mathrm{C}$ (Figure 1c), which confirmed that ketoprofen deterioration did not occur during the manufacturing process and that the excipients used in this study were compatible with ketoprofen.

\section{Influence of surfactants and $\mathrm{pH}$ value of the dissolution medium on ketoprofen solubility}

For the development of sustained-release dosage forms, drug solubility was one of the important factors to be considered, and the solubility profiles of ketoprofen in different $\mathrm{pH}$ media were shown in Figure 2. The comparison of profiles indicated that the solubility profile of ketoprofen was $\mathrm{pH}$-dependent, such that it was poorly soluble in acidic conditions and that the solubility was increased by increasing the $\mathrm{pH}$ value of the medium. Since the solubility of ketoprofen in acidic medium was known to be relatively low, leading to a low dissolution behavior and low bioavailability, various methods have been used to improve the solubility (Ahn et al., 1998; Yamada et al., 2001) and one of the techniques was the incorporation of a small amount of surfactant (Vijaya Kumar et al., 2006). The addition of PVP K30 and SLS resulted in increased drug solubility in different $\mathrm{pH}$ media (Figure 2). Thus, surfactants were added during the pellet manufacturing process, resulting in sustained but complete release of ketoprofen.

\section{Experimental design of the preparation of ketoprofen- loaded microparticles}

During the course of extrusion and spheronization, the microparticle properties were affected by different preparation situations. The variance between different formulations and the effective variables were explored by the L16 $\left(2^{15}\right)$ orthogonal experimental analyses. The results from a duplicate of the experiments are shown in Table 4. For the elongation analyses of microparticles, the important effects were the main effects of $A$ and $E$, such that the amount of water content and spheronization speed were the two important effects that impacted on the elongation of micro particles. The response value of 


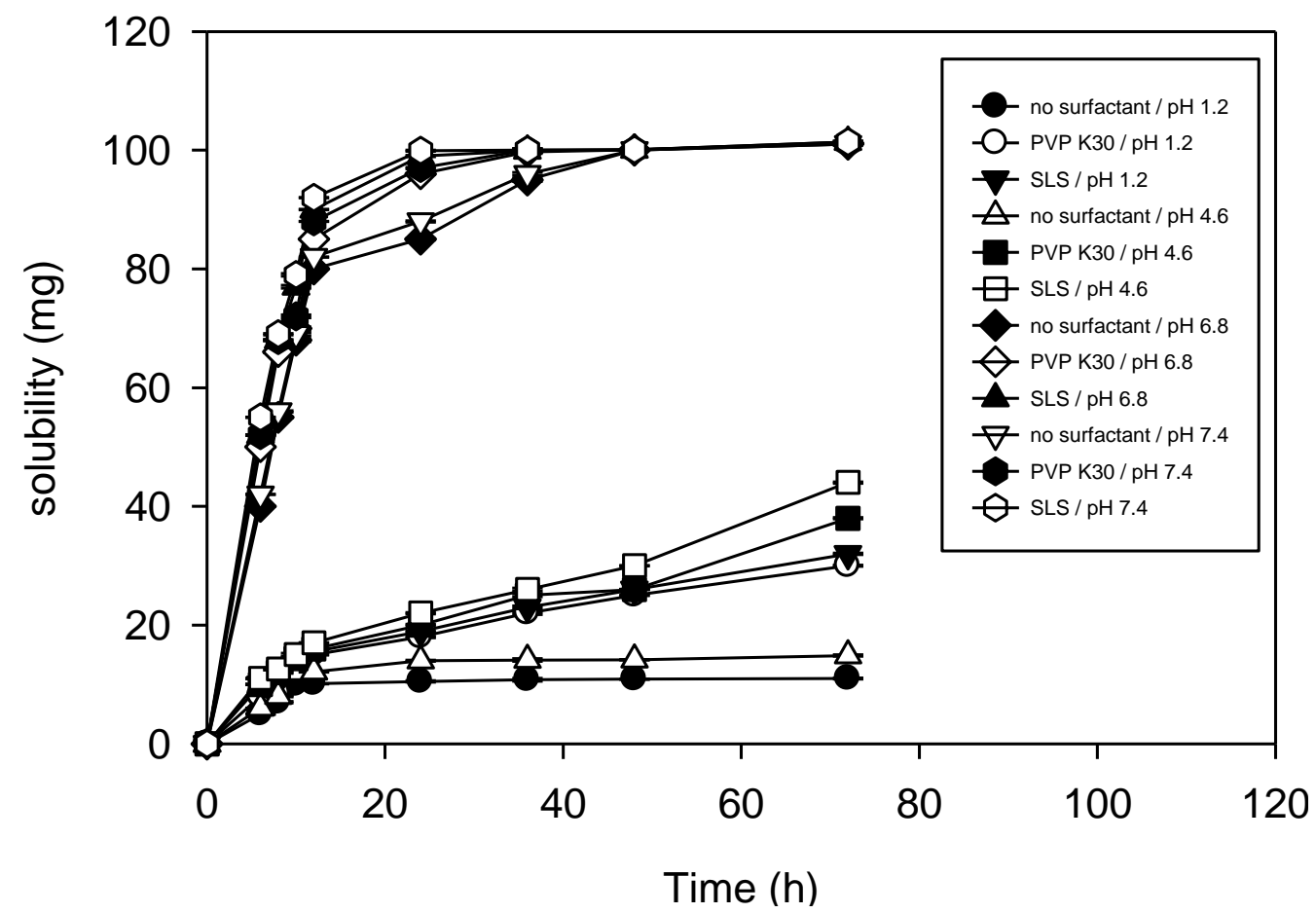

Figure 2. Solubility profile of ketoprofen with different surfactants in different dissolution media.

Table 4. Analysis of variance for elongation and yield percentage of pellets prepared by extrusion-spheronization.

\begin{tabular}{lccccccccc}
\hline \multirow{2}{*}{$\begin{array}{l}\text { Source of } \\
\text { Variation }\end{array}$} & $\begin{array}{c}\text { Degrees } \\
\text { of } \\
\text { Freedom }\end{array}$ & $\begin{array}{c}\text { Sum of } \\
\text { Squares }\end{array}$ & $\begin{array}{c}\text { Mean } \\
\text { square }\end{array}$ & $\mathbf{F}$ & prob $>\mathbf{F}^{\mathbf{b}}$ & $\begin{array}{c}\text { Sum of } \\
\text { Squares }\end{array}$ & $\begin{array}{c}\text { Mean } \\
\text { square }\end{array}$ & $\mathbf{F}$ & prob $>\mathbf{F}^{\mathbf{b}}$ \\
\hline $\mathrm{A}$ & 1 & 0.23 & 0.23 & $5.94^{*}$ & 0.0375 & 2040.33 & 2040.33 & $13.28^{*}$ & 0.0054 \\
$\mathrm{~B}$ & 1 & 0.025 & 0.025 & 0.65 & 0.4400 & 950.80 & 950.80 & $6.19^{*}$ & 0.0346 \\
$\mathrm{C}$ & 1 & $2.40 \times 10^{-3}$ & $2.40 \times 10^{-3}$ & 0.062 & 0.8097 & 5.5 & 5.5 & 0.036 & 0.8542 \\
$\mathrm{D}$ & 1 & $7.89 \times 10^{-4}$ & $7.89 \times 10^{-4}$ & 0.020 & 0.8901 & 540.10 & 540.10 & 3.51 & 0.0936 \\
$\mathrm{E}$ & 1 & 0.63 & 0.63 & $16.16^{*}$ & 0.0030 & 14.25 & 14.25 & 0.093 & 0.7676 \\
$\mathrm{~F}$ & 1 & 0.037 & 0.037 & 0.96 & 0.3539 & 11.12 & 11.12 & 0.072 & 0.7940 \\
Residual & 9 & 0.35 & 0.039 & $5.94^{*}$ & & 1382.99 & 153.67 & & \\
Total & 15 & 1.28 & & 0.65 & & 4945.80 & & & \\
\hline
\end{tabular}

${ }^{*}$ Significant; ${ }^{b} p<0.0500$.

the effects showed that the effects of variables $A$ and $E$ were negative (Figure $3 a$ and $b$ ). Increased variables $A$ and $E$ led to decreased elongation of microparticles and exhibited the best results arising from the low level of water content and spheronizing speed.

For the yield studies (Table 4), the important effects seemed to be variable A (amount of water content) and variable B (amount of binder). These two effects were positive for yield percentage and increasing them led to increased yields of microparticles (Figure $3 c$ and d). According to the analyses aforementioned, in ketoprofen microparticles prepared under optimal conditions, the extrude speed, extrude screen size, and spheronization time did not have significant effects on the response studied. Thus, these variables could be fixed at convenient levels. The SEM photomicrograph of resultant microparticles showed a bit of roughness on the surface but fine elongation behavior (Figure 4).

\section{Yield percentage and content uniformity of different formulations}

The yield percentages of microparticles are shown in Table 5. Comparing the yield percentages of sustainedrelease microparticles prepared by different methods, the 
(a)

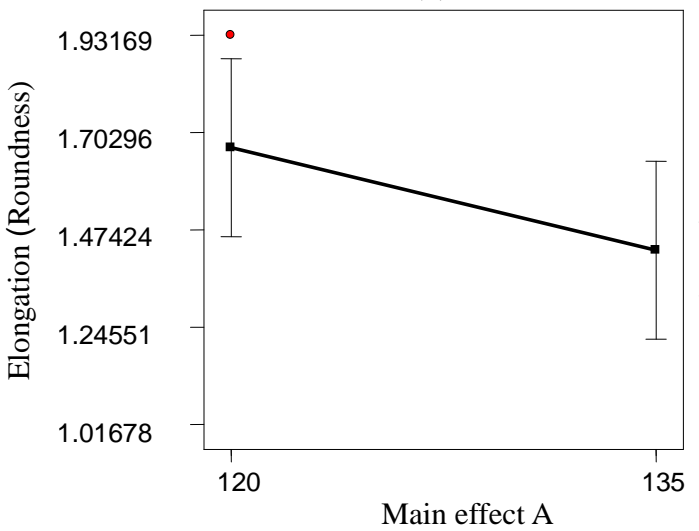

(c)

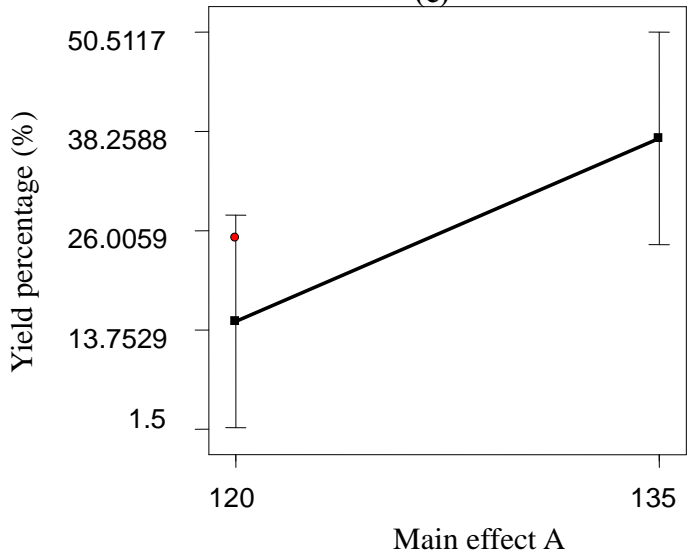

(b)

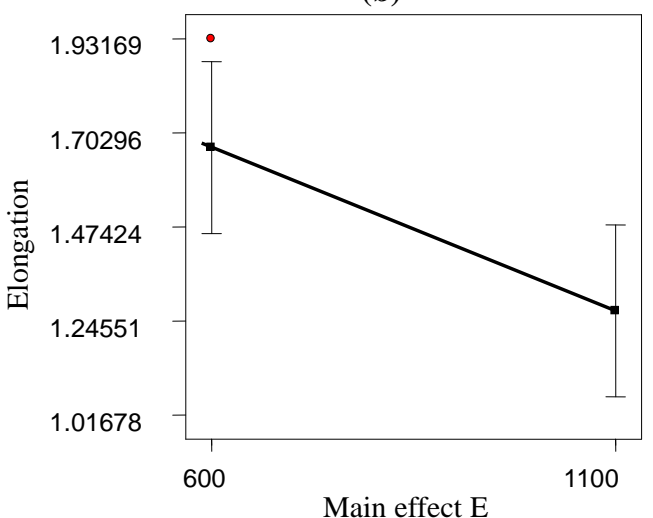

(d)

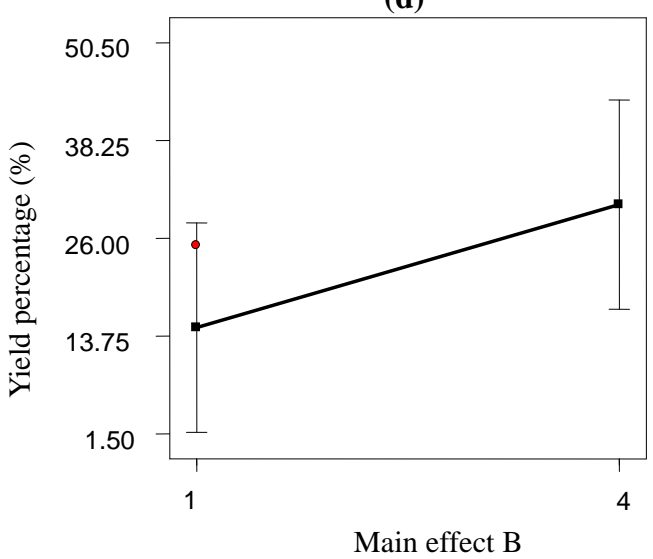

Figure 3. (a-b) Plots of elongation for water content (effect A) and spheronization speed (effect E), respectively. (c-d) Plots of yield percentage for water content (effect A) and amount of binder (effect B), respectively.

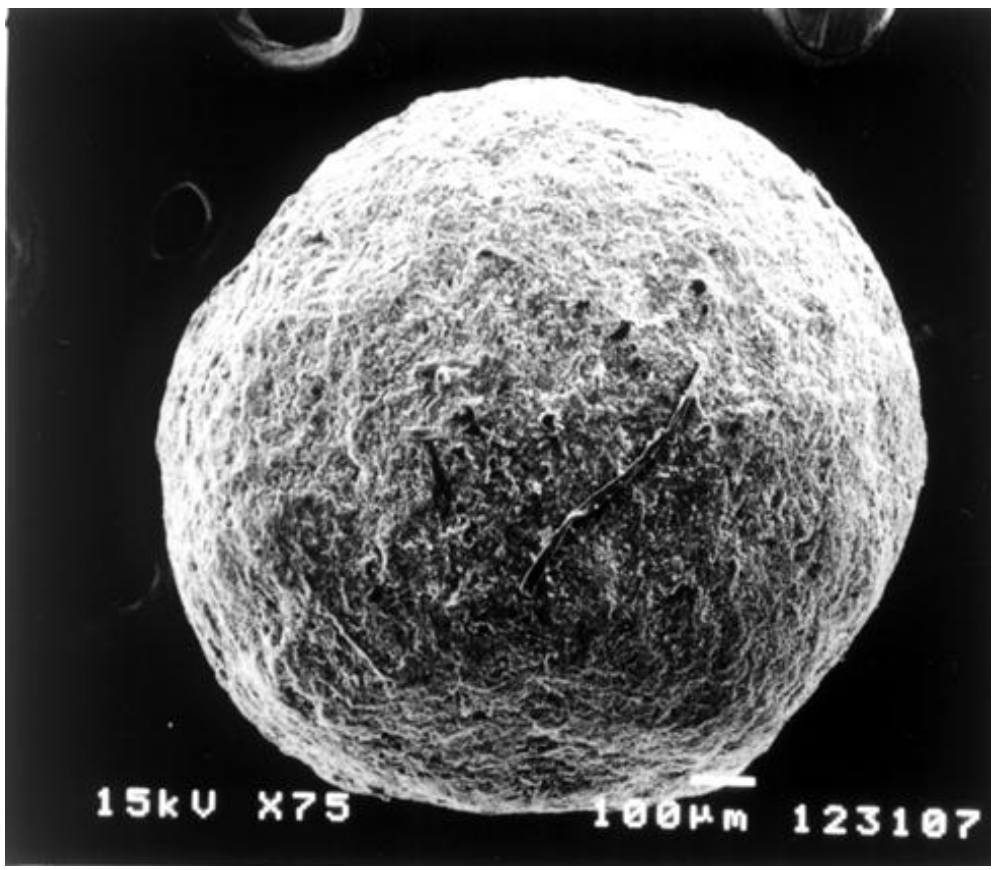

Figure 4. SEM photograph of E-N microparticles. 
Table 5. Yield percentage and content uniformity of different formulations.

\begin{tabular}{lcccc}
\hline \multirow{2}{*}{ Formulation } & $\begin{array}{c}\text { Yield percentage } \\
(\%)\end{array}$ & \multicolumn{3}{c}{ content uniformity } \\
\cline { 3 - 5 } & 97.82 & 96.65 & 2.88 & 0.98 \\
\hline E-N & 83.49 & 95.23 & 3.98 & 1.33 \\
E-S 20 & 88.28 & 93.19 & 1.34 & 2.45 \\
E-S 50 & 99.06 & 98.02 & 2.95 & 1.05 \\
F-N & 92.45 & 95.05 & 3.65 & 1.92 \\
F-S 20 & 91.53 & 95.94 & 2.53 & 1.48 \\
F-S 50 & & & & \\
\hline
\end{tabular}

(a)

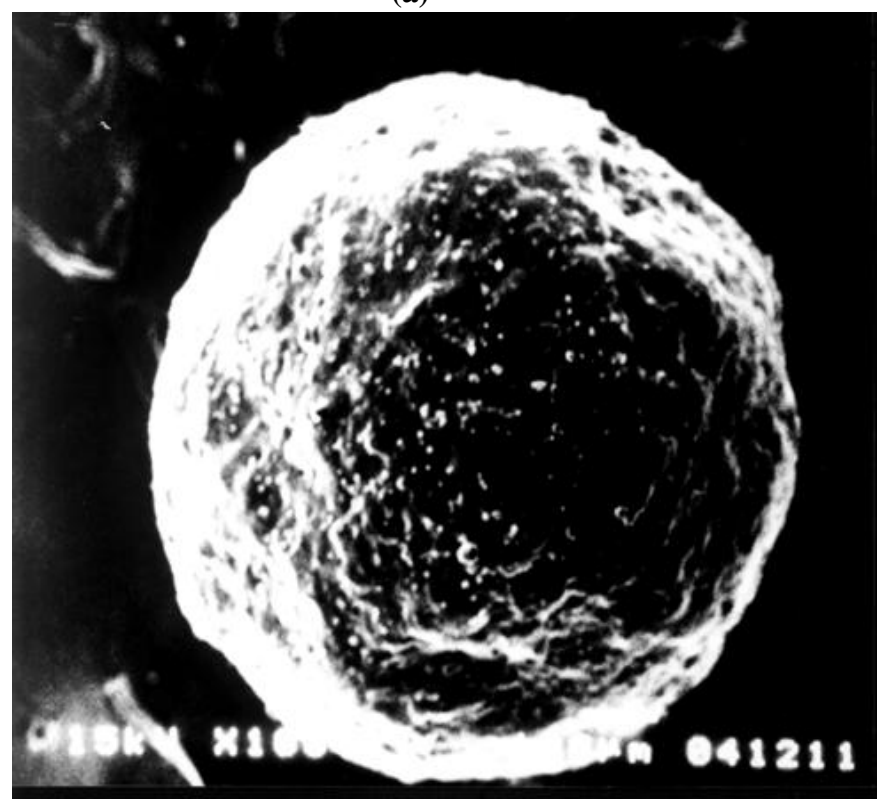

(b)

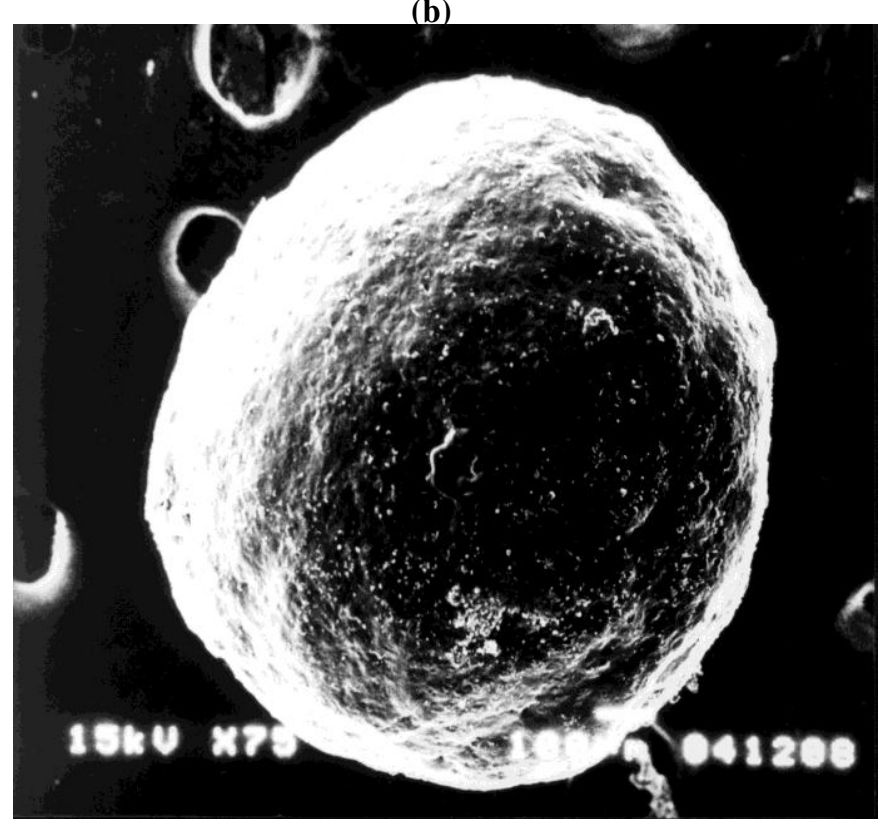

Figure 5. SEM photograph of (a) E-S 20 and (b) E-S 50 microparticles. yields of microparticles prepared by the fluid bed method (F-S 20 and F-S 50) were higher than those of microparticles prepared by the extrusion-spheronization method (E-S 20 and E-S 50). The contents of different microparticles were between 93 to $98 \%$, with less than $5 \%$ coefficient of variation (Table 5). There was no difference in terms of content uniformity of the resultant microparticles among different manufacturing procedures.

\section{Morphological analysis of ketoprofen sustained- release microparticles}

The shape and surface of microparticles prepared by extrusion-spheronization and fluid bed method with different amounts of Surelease ${ }^{\circledR}$ were examined using a scanning electron microscope (Figures 5 and 6). The surface of microparticles prepared by the fluid bed method was smoother compared to that of microparticles prepared by the extrusion-spheronization method. This might be because the surface of non-pareil seeds used by the fluid bed method was smoother than the uncoated micro-particle prepared by extrusion-spheronization, resulting in smoother surface of the resulting "coated microparticles". However, these surface phenomena were not related to drug release rates because ethylcellulose had high tensile strength (Piao et al., 2010).

\section{Drug release for different microparticles}

The different amounts of Surelease ${ }^{\circledR}(20$ and $50 \mathrm{~g})$ used in the manufacturing processes were varied to investigate their effect on the drug release properties. The dissolution profiles obtained with the six formulations (E-N, E-S 20, E-S 50, F-N, F-S 20, F-S 50), as compared to Oruvail $200^{\circledR}$ commercial formulation in $\mathrm{pH} 1.2$ and 6.8 conditions, are shown in Figure $7 a$ and $b$. The release profiles from different formulation in $\mathrm{pH} 6.8$ dissolution medium exhibited finer dissolution behavior than $\mathrm{pH} 1.2$ dissolution medium, namely the effect of $\mathrm{pH}$ value of the dissolution medium on the release characteristics of ketoprofen was distinct. Comparing the release characteristics of different formulations under $\mathrm{pH} 1.2$ dissolution 
(a)

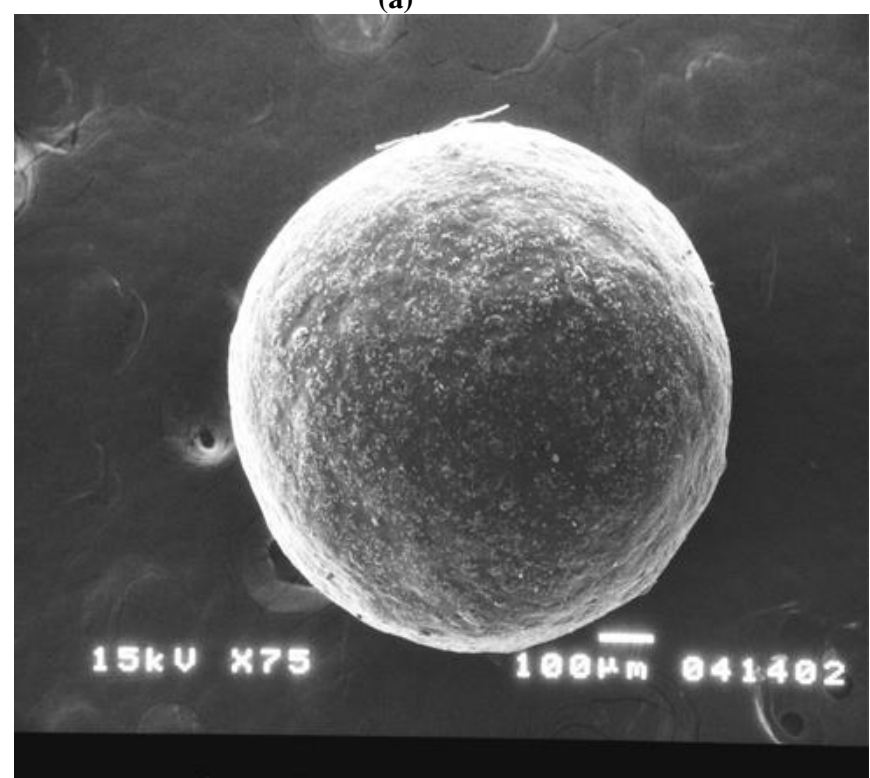

(b)

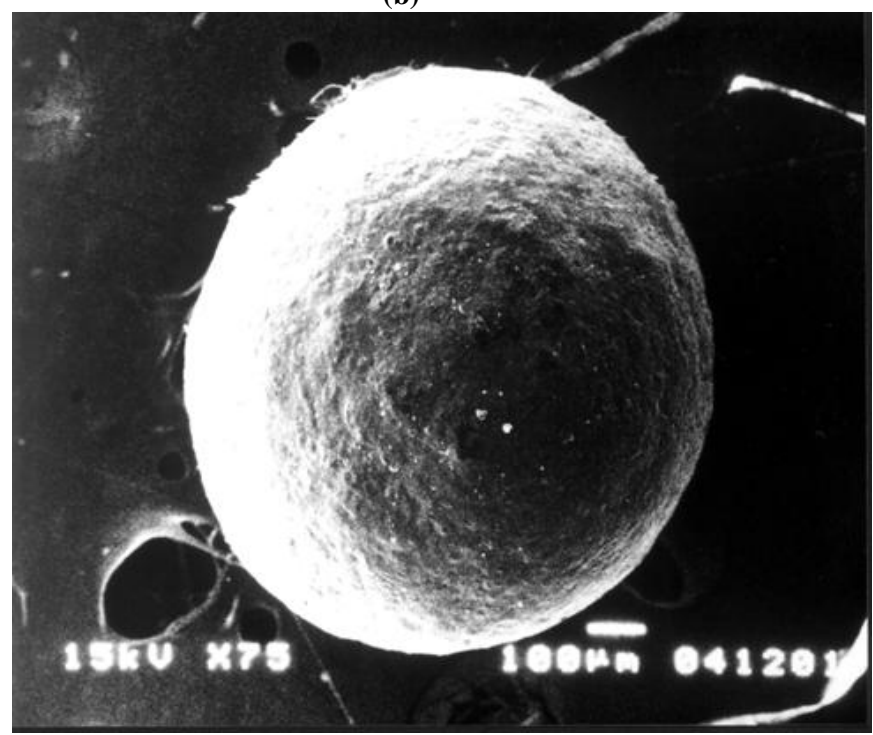

Figure 6. SEM photograph of (a) F-S 20 and (b) F-S 50 microparticles.

conditions, the dissolution profiles of six formulations were similar and very low, only nearly $30 \%$ of the total amount of ketoprofen released at $24 \mathrm{~h}$ after the start of the release test, while Oruvail $200^{\circledR}$ only had $20 \%$ released. This was identical to the results of the solubility test.

In $\mathrm{pH} 1.2$ medium, the dissolution profiles of six formulations were similar and practically independent of composition and quantity of coating. The main limiting factor was very poor solubility of ketoprofen in acidic medium. The cause of the higher dissolution profiles of the six formulations compared to that of Oruvail $200^{\circledR}$ might be attributed to surfactants added in the manufacturing process. The diffusion and release properties (a)

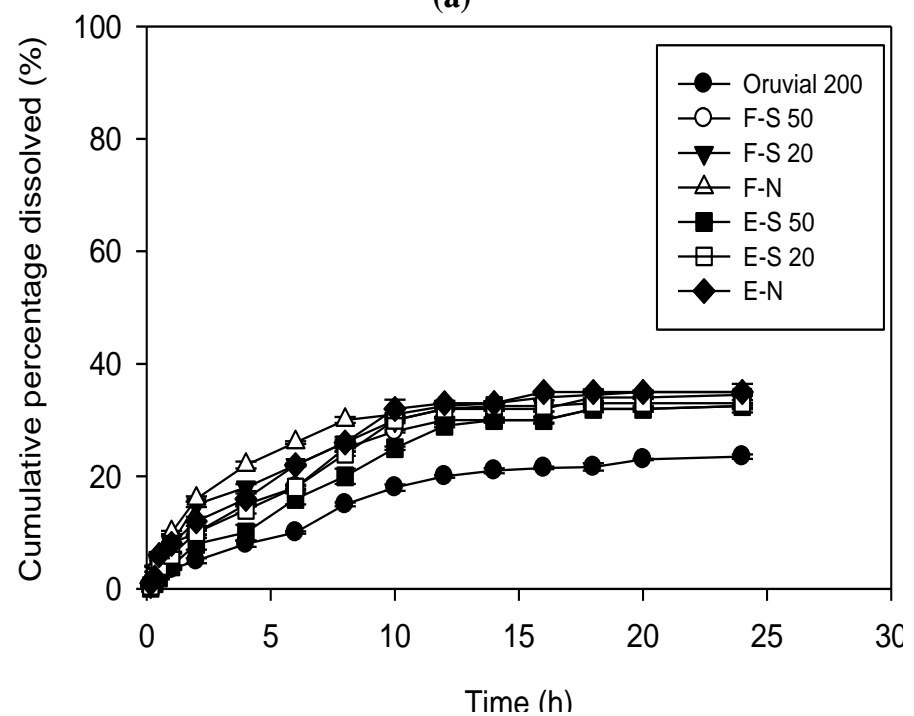

(b)

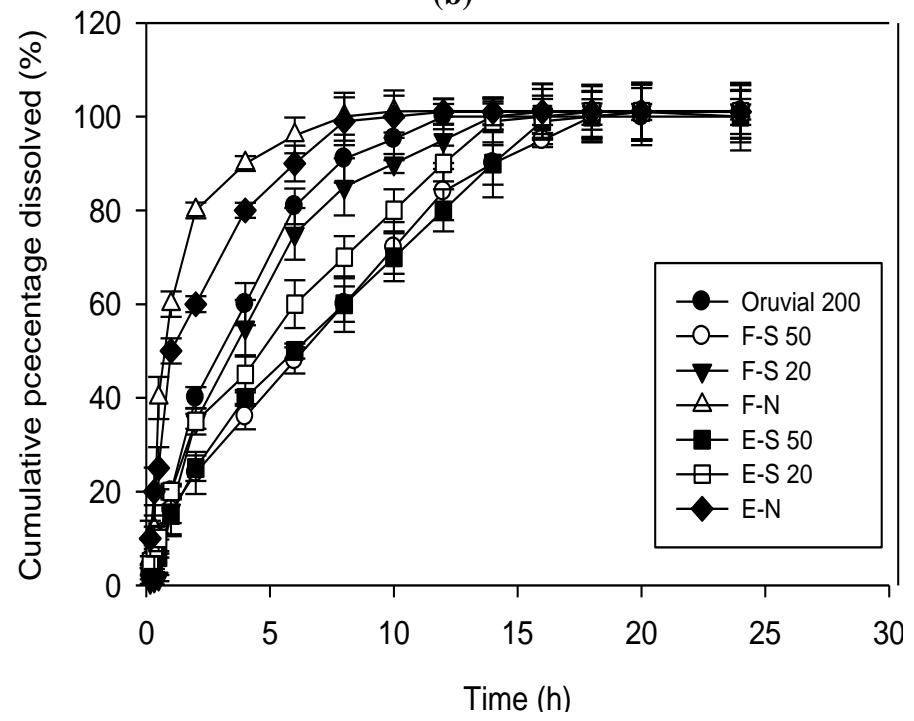

Figure 7. Release profile of different formulations and Oruvial $200^{\circledR}$ at (a) $\mathrm{pH} 1.2$ and (b) $\mathrm{pH} 6.8$ dissolution media. - Oruvial $200^{\circledR}$; ○ FS 50; $\nabla$ F-S 20; $\triangle$ F-N; - E-S 50; $\square$ E-S 20; $\bullet$ E-N.

of insoluble active compounds were improved significantly to obtain enough solubility and release rate for the desired bioavailability (Li et al., 2006). On the other hand, in $\mathrm{pH} 6.8$ dissolution medium, the micro- particles uncoated by Surelease ${ }^{\circledR}$ (F-N and E-N) exhibited fastest release rates. The E-S and F-N formulations dissolved rapidly and efficiently (around 60 and $80 \%$, respectively, of the drug was released during the first $2 h$ ), and the cumulative drug release percent could be increased to $100 \%$ within 8 and $12 \mathrm{~h}$, respectively.

For other formulations, the following rank order concerning ketoprofen release rate was noted: $\mathrm{F}-\mathrm{N}>\mathrm{E}-\mathrm{N}>\mathrm{F}$ S $20>$ E-S $20>$ Oruvail $200^{\circledR}>$ E-S 50 or F-S 50 . The dissolution profiles of E-S 50 and F-S 50 exhibited faster kinetics in the first $1 \mathrm{~h}$ period, faster when the slope was 
(a)

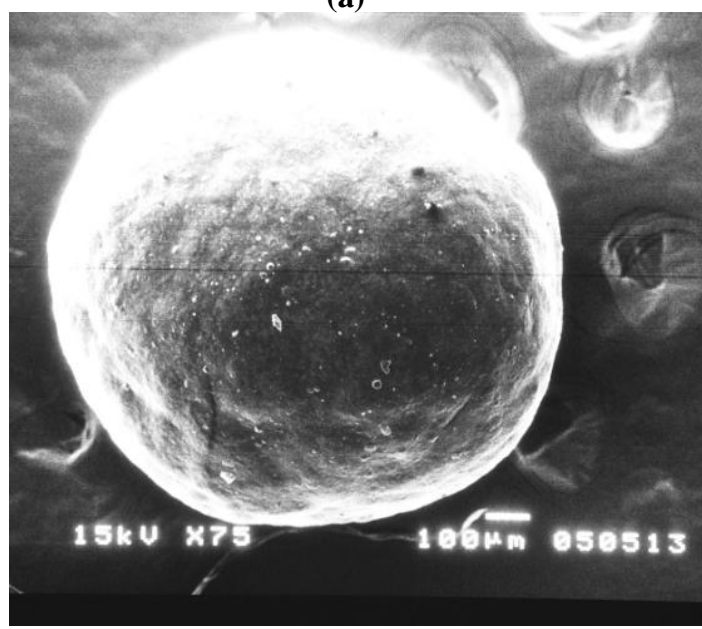

(c)

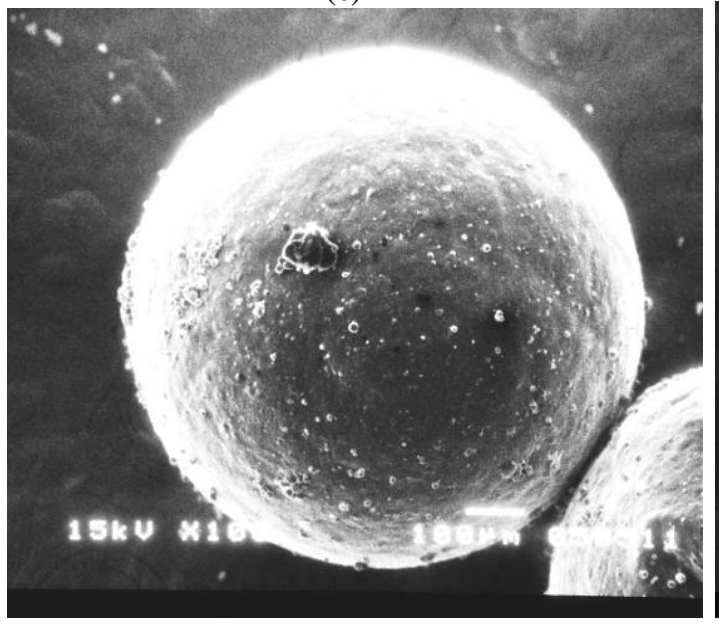

(b)

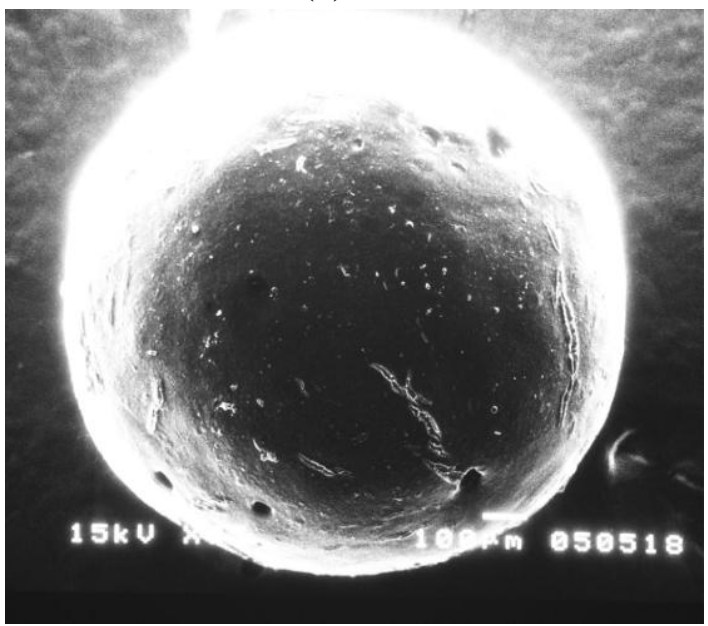

(e)

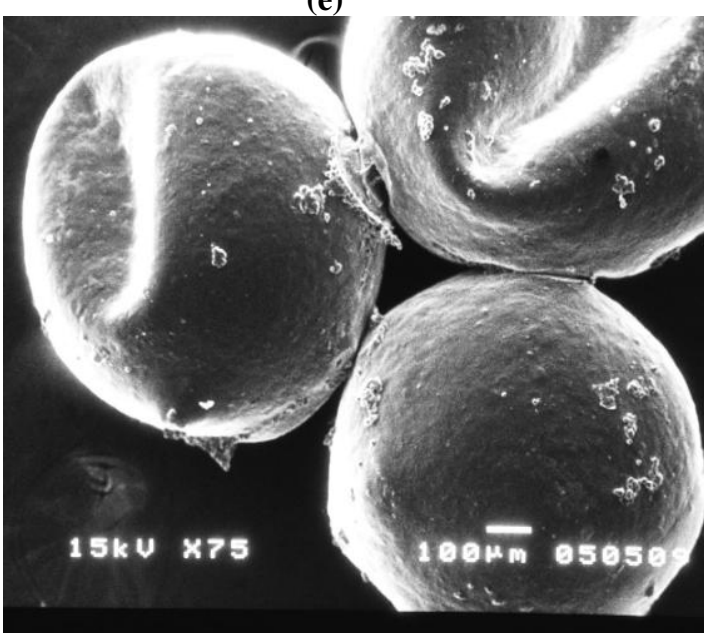

Figure 8. SEM photograph of microparticles after dissolution test (a) E-S 20, (b) E-S 50, (c) F-S 20, and (d) F-S 50 .

reduced such that after $18 \mathrm{~h}$, almost $100 \%$ of ketoprofen was dissolved. The release data were analyzed as per zero-order, first-order, Higuchi and Korsmeyer-Peppas models. The correlation coefficients $\left(R^{2}\right)$ of various kinetic models are given in Table 8. For all Surelease ${ }^{\circledR}$ coated formulations, the Higuchi square root model had the best fit with higher correlation $\left(r^{2}>0.98\right)$. When the release data were analyzed as Korsmeyer-Peppas equation, the $\mathrm{n}$ values of all formulations ranged between $0.53-0.84$. The surface and morphology of microparticles after completing the release test in $\mathrm{pH} 6.8$ medium were examined and the photomicrographs corresponding to $\mathrm{E}$ S 20, E-S 50, F-S 20 and F-S 50 (Figure 8a to d, respectively) revealed that Surelease ${ }^{\circledR}$ was insoluble in water. The sunken surface was fabricated manually to show a hollow structure caused by the dissolution of ketoprofen and non-pareil seeds (Figure 8d). This might confirm that the release mechanism of coated microparticles was controlled by diffusion of the Surelease ${ }^{\circledR}$ membrane.

\section{DISCUSSION}

Comparing the pharmaceutical characteristics of resulting sustained-release microparticles, the results showed variances between microparticles prepared by different methods. Due to the narrow size distribution and preferable flow behavior of core microparticles prepared by the fluid bed method, these microparticles (F-S 20 and F-S 50) have higher yields than those prepared by extrusion-spheronization (E-S 20 and E-S 50). The core microparticles prepared by extrusion-spheronization are heavier, resulting in fewer amounts of microparticles to be blown up under the coating process and in reduced coating yield percentage. This phenomenon can be improved by increasing the quantity of core microparticles and by reducing the spraying flow rate. By increasing the 
Table 6. Difference factors $\left(f_{1}\right)$ and similarity factor $\left(f_{2}\right)$ of microparticles prepared by different Surelease ${ }^{\circledR}$ amounts.

\begin{tabular}{lcccc}
\hline \multirow{2}{*}{ Formulations } & \multicolumn{2}{c}{ pH 1.2 } & \multicolumn{2}{c}{ pH 6.8 } \\
\cline { 2 - 5 } & $\boldsymbol{f}_{\boldsymbol{1}}$ & $\boldsymbol{f}_{\boldsymbol{2}}$ & $\boldsymbol{f}_{\boldsymbol{1}}$ & $\boldsymbol{f}_{\boldsymbol{2}}$ \\
\hline E-N / F-N & 7.296 & 56.983 & 7.378 & 55.935 \\
E-S 20 / F-S 20 & 6.727 & 61.834 & 8.430 & 56.407 \\
E-S 50 / F-S 50 & 7.554 & 56.682 & 2.622 & 81.612 \\
\hline
\end{tabular}

Table 7. Difference factors $\left(f_{1}\right)$ and similarity factor $\left(f_{2}\right)$ of six formulations and Oruvial $200^{\circledR}$.

\begin{tabular}{lcccc}
\hline \multirow{2}{*}{ Formulations } & \multicolumn{2}{c}{ pH 1.2 } & \multicolumn{2}{c}{ pH 6.8 } \\
\cline { 2 - 5 } & $\boldsymbol{f}_{\boldsymbol{1}}$ & $\boldsymbol{f}_{\boldsymbol{2}}$ & $\boldsymbol{f}_{\boldsymbol{1}}$ & $\boldsymbol{f}_{\boldsymbol{2}}$ \\
\hline E-N & 69.83 & 69.83 & 13.47 & 44.91 \\
E-S 20 & 56.23 & 56.23 & 9.61 & 50.04 \\
E-S 50 & 40.98 & 40.98 & 16.38 & 40.09 \\
F-N & 79.32 & 79.32 & 18.67 & 36.03 \\
F-S 20 & 66.24 & 66.24 & 5.41 & 67.46 \\
F-S 50 & 52.25 & 52.25 & 16.88 & 39.77 \\
\hline
\end{tabular}

amount of Surelease ${ }^{\circledR}$, the coating on microparticles surfaces has a remarkable effect in delaying the release of ketoprofen. This is obviously predictable such that an increase in the polymer proportion results in increased micro-particle coating layer and thus, in decreased drug diffusion and a reduction in drug release rate.

On the other hand, comparing the release characteristics of microparticles with the same amount of Surelease ${ }^{\circledR}$ but prepared by different procedures, microparticles prepared by extrusion-spheronization displayed a slower release rate. The release rate of E-S 20 was slower than that of F-S 20 and E-S 50 was slower than F$S$ 50. The possible reason may be the structural differences by the manufacturing processes. Ketoprofen are dispersed on the coating on the surface of non-pareil seeds for the fluid bed method, while ketoprofen are embedded in microparticles prepared by extrusionspheronization. This phenomenon results in the increased drug diffusion path of microparticles prepared by extrusion-spheronization, and the reduced drug release rate, which is especially distinct for microparticles without Surelease ${ }^{\circledR}$ (E-S, F-S).

Based on the increase in Surelease ${ }^{\circledR}$, the effect of diffused mechanism control by the coating membrane is more effective than the location of ketoprofen. Therefore, the release profiles of F-N 50 and E-N 50 formulations, which are coated by larger amounts of Surelease ${ }^{\circledR}$ and are almost identical, showed that the release rate is insignificantly affected by manufacturing process. Drug diffusion from the coating film is the main parameter affecting release rate. This correlation is confirmed using difference factors $\left(f_{1}\right)$ and similarity factor $\left(f_{2}\right)$ (Table 6). The $f_{1}$ values range from 2.622 to 8.430 and the $f_{2}$ value between 55.935 and 81.612 , suggesting that all of the formulations coated with same amount Surelease ${ }^{\circledR}$ showed similar release behavior, while the release profiles of E-S 50 and F-S 50 are almost the same because the $f_{1}$ value approaches zero $\left(f_{1}=2.622\right)$ and the $f_{2}$ value is nearly $100\left(f_{2}=81.612\right)$.

Furthermore, fit factors are also used to evaluate the difference between all formulations and commercial Oruvail $200^{\circledR}$ (Table 7). The release characteristic of all formulations is not similar for Oruvail $200^{\circledR}$ in $\mathrm{pH} 1.2$ medium, whereas in $\mathrm{pH} 6.8$ medium, the release characteristic of microparticles coated with $20 \mathrm{~g}$ Surelease $^{\circledR}$ (E-S 20 and F-S 20) was similar to that of Oruvail $200^{\circledR}$. In fact, F-S 20 has the most similar formulation because the $f_{1}$ and $f_{2}$ values are 5.41 and 67.46, respectively. The Higuchi square root model for all Surelease ${ }^{\circledR}$ coating formulations had the best fit with higher correlation $\left(r^{2}>0.98\right)$, which was commonly regarded as drug release following a diffusion-controlled mechanism (Korsmeyer et al., 1983; Wang et al., 2011). When the release data were analyzed as per KorsmeyerPeppas equation, the $n$ value was found in the range $0.62-0.82$ with none and smaller Surelease ${ }^{\circledR}$ coated microparticles (E-N, F-N, E-S 20 and F-S 20), indicating non-Fickian diffusion as the mechanism from these microparticles. Whereas in the case of microparticles prepared with larger Surelease ${ }^{\circledR}$ (E-S 50 and F-S 50), the $\mathrm{n}$ value was in the range $0.83-0.85$, indicating that the mechanism of drug release from formulation E-S 50 and F-S 50 were found to be close to zero order release kinetics. As shown in Figure 8b, it is obvious that the release kinetic model of E-S 50 and F-S 50 are near the zero-order model after $1 \mathrm{~h}$ of the release test, characterized by a constant slope of the release curve.

During the 1 and $12 \mathrm{~h}$ periods of the release profile, the values of the correlation coefficient are 0.9941 and 0.9994 for E-S 50 and F-S 50, respectively. The trend towards a zero-order release model of microparticles can be attributed to the larger Surelease ${ }^{\circledR}$ coating such that the release mechanism is controlled by the membrane independent of time (Yamada et al., 2001). The smaller Surelease ${ }^{\circledR}$ coated micro-particles exhibited as the Fickian or non-Fickian release mode was released by pure diffusion or diffusion coupled with erosion of a drug out of an encapsulating matrix (Lee, 1985; Ritger and Peppas, 1987a; Ritger and Peppas, 1987b; Wang et al., 2011). Therefore, it is feasible to modify the release rate and kinetic model by adjusting the coating amount of Surelease ${ }^{\circledR}$. While the different manufacturing methods displayed different pharmaceutical characteristics and release rates, no influence was observed on release kinetics.

\section{Conclusion}

The structural differences between microparticles manufactured by the extrusion-spheronization and fluid-bed 
Table 8. In vitro release kinetics of ketoprofen from six microparticles and Oruvial $200^{\circledR}$.

\begin{tabular}{|c|c|c|c|c|c|c|c|c|c|c|}
\hline \multirow{3}{*}{ Formulations } & \multicolumn{5}{|c|}{ pH 1.2} & \multicolumn{5}{|c|}{$\mathrm{pH} 6.8$} \\
\hline & \multirow{2}{*}{$\begin{array}{c}\text { Zero order } \\
\mathbf{R}^{2} \\
\end{array}$} & \multirow{2}{*}{$\begin{array}{c}\text { First order } \\
\mathbf{R}^{2} \\
\end{array}$} & \multirow{2}{*}{$\begin{array}{c}\text { Higuchi } \\
\mathrm{R}^{2}\end{array}$} & \multicolumn{2}{|c|}{ Korsmeyer-Peppas } & \multirow{2}{*}{$\begin{array}{c}\text { Zero order } \\
\mathbf{R}^{2} \\
\end{array}$} & \multirow{2}{*}{$\begin{array}{c}\text { First order } \\
\mathbf{R}^{2} \\
\end{array}$} & \multirow{2}{*}{$\begin{array}{c}\text { Higuchi } \\
\mathbf{R}^{2}\end{array}$} & \multicolumn{2}{|c|}{ Korsmeyer-Peppas } \\
\hline & & & & $\mathrm{R}^{2}$ & $n$ & & & & $\mathbf{R}^{2}$ & $n$ \\
\hline Oruvial $200^{\circledast}$ & 0.9559 & 0.5887 & 0.9914 & 0.9945 & 0.5694 & 0.9693 & 0.7553 & 0.9926 & 0.9867 & 0.8255 \\
\hline E-N & 0.8838 & 0.6128 & 0.9777 & 0.9941 & 0.6322 & 0.8886 & 0.7639 & 0.9547 & 0.9656 & 0.7374 \\
\hline E-S 20 & 0.9793 & 0.6201 & 0.9957 & 0.9768 & 0.7067 & 0.9518 & 0.7829 & 0.9907 & 0.9889 & 0.8106 \\
\hline E-S 50 & 0.9632 & 0.6395 & 0.9912 & 0.9756 & 0.8418 & 0.9664 & 0.7397 & 0.9982 & 0.9842 & 0.8432 \\
\hline F-N & 0.9224 & 0.5305 & 0.9898 & 0.9835 & 0.6169 & 0.9169 & 0.813 & 0.9361 & 0.9635 & 0.6888 \\
\hline F-S 20 & 0.8857 & 0.6137 & 0.9801 & 0.9549 & 0.6421 & 0.9655 & 0.7453 & 0.9805 & 0.9766 & 0.8207 \\
\hline F-S 50 & 0.9377 & 0.6306 & 0.9913 & 0.9737 & 0.8338 & 0.9749 & 0.7368 & 0.9947 & 0.9674 & 0.8471 \\
\hline
\end{tabular}

methods resulted in different dissolution rates, while different Surelease $\AA$ amounts resulted in different release kinetics. It is feasible to adjust the release characteristics by utilizing different operating conditions and ingredients, including surfactant and sustained-release materials. The findings obtained herein could be useful in understanding the release behavior differences and as guidelines for selecting processing methods in the preparation of sustained-release microparticles.

\section{REFERENCES}

Abdullah ME, Al-Khamis KI (1993). Micro-computer program for the assessment of one-way, two-way and factorial analysis of variance in pharmaceutical data. Comput. Methods Programs Biomed. 41:131-133.

Ahn HJ, Kim KM, Kim CK (1998). Enhancement of bioavailability of ketoprofen using dry elixir as a novel dosage form. Drug Dev. Ind. Pharm. 24: 697-701

Ansel HC, Allen Jr. LV, Popovich N (1999). Pharmaceutical Dosage Forms and Drug Delivery Systems. $7^{\text {th }}$ ed. New York: Lippincott Williams and Wilkins.

Baert L, Vermeersch H, Remon JP, Smeyers-Verbeke J, Massart D L (1993). Study of parameters important in the spheronization process. Int. J. Pharm. 96:225-229.

Blanque D, Sternagel H, Podczeck F, Newton JM (1995). Some factors influencing the formation and in vitro drug release from matrix pellets prepared by extrusion/ spheronization. Int. J. Pharm. 119:203-211.

Bodea A, Leucuta SE (1997). Optimization of propranolo hydrochloride sustained release pellets using a factorial design. Int. J. Pharm. 154:49-57.

Bodea A, Leucuta SE (1998). Optimization of propranolo hydrochloride sustained-release pellets using Box-Behnken design and desirability function. Drug Dev. Ind. Pharm. 24:145-155.

Costa P, Sousa Lobo JM (2001). Modeling and comparison of dissolution profiles. Eur. J. Pharm. Sci. 13:123-133.

Esposito E, Roncarati R, Cortesi R, Cervellati F, Nastruzzi C (2000). Production of Eudragit microparticles by spraydrying technique: Influence of experimental parameters on morphological and dimensional characteristics. Pharm. Dev. Technol. 5:267-278.

Follonier N, Doelker E (1992). Biopharmaceutical comparison of oral multiple-unit and single unit sustained release dosage forms. STP Pharm. Sci. 2:141-155.

Gandhi R, Lal Kaul C, Panchagnula R (1999). Extrusion and spheronization in oral controlled-release dosage forms. Pharm. Sci. Technol. Today 4:160-170.

Goskonda VR, Reddy IK, Durrani MJ, Wilber W, Khan MA (1998). Solid-state stability assessment of controlled release ablets containing Carbopol $^{\circledR}$ 971P. J. Control. Release 54:87-93.

Hamdani J, Moës AJ, Amighi K (1996). Development and in vitro evaluation of a novel floating multiple unit dosage form obtained by melt pelletization. Int. J. Pharm. 322:96-103.

Hassan EE, Eshra AG, Nada AH (1995). Formulation of prolonged release lipid micro-pellets by emulsion congealing: Optimization of ketoprofen entrapment and release. Int. J. Pharm. 121:149-155.

Hellén L, Yliruusi J (1993). Process variables of instant granulator and spheronizer: III. Shape and shape distributions of pellets. Int. J. Pharm. 96:217-223.

Higuchi T (1963). Mechanism of sustained release medication: theoretical analysis of rate of release of solid drugs dispersed in solid matrices. J. Pharm. Sci. 52:1145-1149.

Hileman GA, Goskonda SR, Spalitto AJ, Upadrashta SM (1993). A factorial approach to high dose product development by an extrusion/spheronization process. Drug Dev. Ind. Pharm. 19:483-491.

Jiménez-Aguilar DM, Ortega-Regules A E,. Lozada-Ramírez JD, Pérez-Pérez $\mathrm{MCl}$, Vernon-Carter EJ, Welti-Chanes J (2011). Color and Chemical Stability of Spray-dried Blueberry Extract Using Mesquite Gum as Wall Material. J. Food Compost. Anal. 24(6):889-894

Jinno J, Oh DM, Crison JR, Amidon GL (2000). Dissolution of ionizable water-insoluble drugs: The combined effect of $\mathrm{pH}$ and surfactant. J. Pharm. Sci. 89:268-274.

Koo OMY, Heng PWS (2001). The influence of microcrystalline cellulose grade on shape and shape distribution of pellets produced by extrusion-spheronization. Chem. Pharm. Bull. 49(11):1383-1387.

Korsmeyer RW, Gurny R, Doelker E, Buri P, Peppas NA (1983). Mechanisms of solute release from porous hydrophilic polymers. Int. J. Pharm. 15:25-35

Lee PI (1985). Kinetics of drug release from hydrogel matrices. J. Control. Release 2:277-288.

Li F Q, Hu JH, Deng JX, Su H, Xu S, Liu JY (2006). In vitro controlled release of sodium ferulate from Compritol 888 ATO-based matrix tablets. Int. J. Pharm. 324:152-157.

Marmo L (2007). Low temperature drying of pomace in spout and spout-fluid beds. J. Food Eng., 79(4): 1179-1190.

Otsuka M, Gao J, Matsuda Y (1994). Effect of amount of added water during extrusion-spheronization process on 
pharmaceutical properties of granules. Drug Dev. Ind. Pharm. 20:2977-2992.

Piao ZZ, Lee KH, Kim DJ, Lee HG, Lee J, Oh KT, Lee BJ (2010). Comparison of Release-Controlling Efficiency of Polymeric Coating Materials Using Matrix-type Casted Films and Diffusion-Controlled Coated Tablet. AAPS Pharm. Sci. Tech. 11:630-636.

Polli JE, Rekhi GS, Augsburger LL, Shah VP (1997). Methods to compare dissolution profiles and a rationale for wide dissolution specifications for metoprolol tartrate tablets. J. Pharm. Sci. 86:690700.

Ritger PL, Peppas NA (1987a). A simple equation for description of solute release. I. Fickian and non-Fickian release from non-swellable devices in the form of slabs, spheres, cylinders or discs. J. Contr. Release 5:23-36.

Ritger PL, Peppas NA (1987b). A simple equation for description of solute release. II. Fickian and anomalous release from swellable devices. J. Control. Release 5:37-42.

Shailesh TP, Vipul PD, Girishbhai JK, Manish CJ (2010). Preparation and in vitro Evaluation of Ethylcellulose Coated Egg Albumin Microspheres of Diltiazem Hydrochloride. J. Young Pharm. 2:27-34.

Tapia C, Buckton G, Newton JM (1993). Factors influencing the mechanism of release from sustained release matrix pellets, produced by extrusion/spheronization. Int. J. Pharm. 92:211-218.
Vergote GJ, Vervaet C, Van Driessche I, Hoste S, De Smedt S, Demeester J, Jain RA, Remon JP (2001). An oral controlled release matrix pellet formulation containing nano-crystalline ketoprofen. Int. J. Pharm. 219:81-87.

Vergote GJ, Vervaet C, Van Driessche I, Hoste S, De Smedt S, Demeester J, Jain RA, Ruddy S, Remon JP (2002). In vivo evaluation of matrix pellets containing nano-crystalline ketoprofen. Int. J. Pharm. 240:79-84.

Vijaya Kumar SG, Mishra DN (2006). Preparation, characterization and in vitro dissolution studies of solid dispersion of Meloxicam with PEG 6000. Yakugadu Zasshi 126:657-664.

Wang Z, Wu H, Liao C, Zhou N, Cheng W, Wan Y (2011). Sustained release of ketoprofen from fibrous chitosan-poly ( $\varepsilon$-caprolactone) membranes. Carbohydr. Polymers 84:624-630.

Yamada T, Onishi H, Machida Y (2001). Sustained release ketoprofen microparticles with ethylcellulose and carboxymethylcellulose. J. Control. Release 75:271-282. 